\title{
Experimental Investigation and Failure Analysis of Glass Fibre Reinforced Epoxy Composite
}

\author{
Sudhir Shekhar Mathapati ${ }^{1}$, Dr. Suresh $\mathbf{B}^{2}$ \\ ${ }^{1}$ Assistant Professor, Department of Mechanical Engineering, G.H.Raisoni Institute of Engineering \& Technology, \\ Pune- 412207, Maharashtra, India \\ ${ }^{2}$ Associate Professor, Department of Mechanical Engineering, G.H.Raisoni Institute of Engineering \& Technology, \\ Pune- 412207, Maharashtra, India
}

\begin{abstract}
Now a day's composites are important class of materials which are available to mankind. So studies of these composites are played a very important role in engineering, material science, metallurgy and solid mechanics applications. The fiber reinforced polymer composites are more widely used in the automotive industry, aeronautical industry and finds many other industrial applications due to their benefits like low cost, noise control, low weight and ease of processing. The objective of this research is to prepare E-glass fiber based composite with percentage variation of glass fibre content like 1\%, and $2 \%$ with using a bisphenol A as matrix material and conducting flexural test on the composite.
\end{abstract}

Keywords: composite material, material science, automotive, aeronautical, polymer, E-glass

\section{Introduction}

Composite materials are important class of materials which are now available to mankind in large quantity [1]. Composite materials are very much essential for mechanical, chemical, civil engineers, and material scientists for using them on a huge amount of engineering and other applications. Modern composites had started in 1930s [6].

The concept of composite materials is that to combine variety of materials to produce a new material with excellent properties by the individual constituents [3]. In other words Composite materials consist of two or more physically different, suitably set or dispersed phases, with a boundary sorting out them [1]. It contains most important characteristics that are not soluble to each other [2]. Composites materials are usually prepared to create newer materials with different physical, working and mechanical properties, example they may be produced to construct light and strong materials [5].

\section{Necessity of Composites Materials}

Composites materials have its own properties, which could not be achieved by either of the constituent materials alone [4]. So now we can see that composites materials are becoming more important as it can help to improve our quality of product. Composites are widely used in aircrafts and spacecrafts' parts, automobiles, boats, buildings, roads, bridges and many more of other applications [6].

\section{Objectives}

3.1 To investigate the flexural properties of composite reinforced with E-glass fibre.

3.2 To conduct the Flexural test and to study the effect of the addition of the reinforcement in the flexural properties of the material.
3.3 To study an effect of variation percentage of reinforcement on the flexural properties.

\section{Methods of Preparing the Composite Material}

This chapter describes the details of processing of the composites and the experimental procedures followed for their flexural characterization. The raw materials used in this work are,

1) Matrix material

2) E glass fiber (chopped strand mat)

3) Hardener

The fabrications of the composites are carried out through the hand lay-up technique. Composites with percentage variations such as $1 \%$ and $2 \%$ glass fiber are made. Initially take the suitable amount of matrix material and add catalyst, accelerator, hardener and glass fiber to the matrix material. Then mix them properly by using mechanical stirrer, after that allow the mixture for some time to reduce the air bubbles. Then spray up the releasing agent on the surface of the mould and pour the mixture of matrix material into the mould with random orientation.

The material of each composite are cured under a room temperature for 24 hours in the mould. Then this material is post cured in the air for another 24 hours after removing out of the mould. Specimens of suitable dimensions are cut using a mechanical cutter for flexural testing. Maximum care has been taken to maintain uniformity and homogeneity of the composite.

Hand lay-up is a very simple method for composite preparation. The layup method require very little amount of labor requirement. For the limited preparation of composites this method is very suitable. The hand layup process involves, initially reinforcement is in the form of chopped strand mat which is placed inside the mould coated with

\section{Volume 4 Issue 12, December 2015}




\section{International Journal of Science and Research (IJSR) \\ ISSN (Online): 2319-7064 \\ Index Copernicus Value (2013): 6.14 | Impact Factor (2014): 5.611}

releasing agent to avoid the sticking problem. A resin in the liquid form is mixed with a promoter, accelerator and hardener and applied with a roller in such way that the matrix gets into the gaps of the reinforcement. After completion of this method the material is allow to keep in the room temperature for curing. Then this material is post cured in the air for another 24 hours after removing out of the mould.

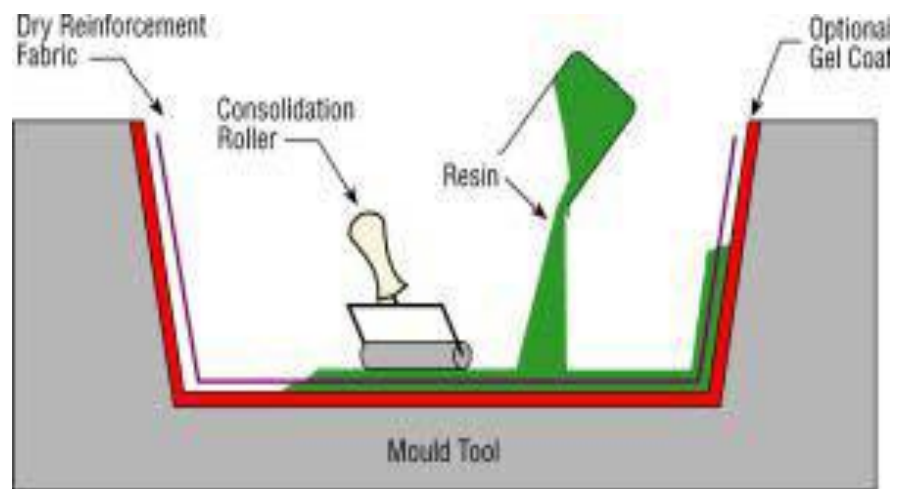

Figure 1: Hand layup process

Figure 1 shows the hand lay-up process. Other processes like vacuum bagging, vacuum molding and compression molding can be used with hand lay-up to improve the quality of the finished part.

\section{Experimental Setup and Conducting the Flexural Test}

Bending tests provide information about the bending (flexural) properties of plastics when employed under conditions approximating those under which the tests are made. The test specimens are prepared for flexural test were cut as per ASTM D 790 specification [6] and the specimens were prepared as shown in figure 2.

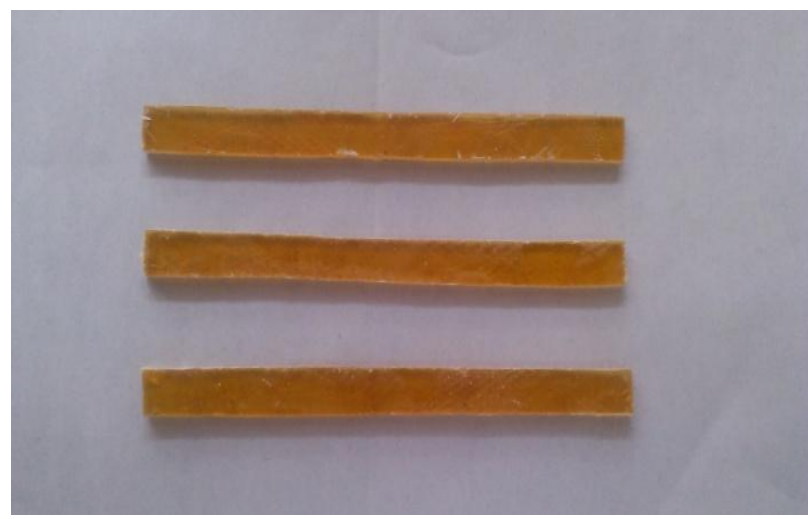

Figure 2: Specimens for bending test

The universal testing machine set-up chosen has maximum loading capacity of $100 \mathrm{kN}$. The arrangement for bending test is shown in figure 3 . The machine has two crossheads one is adjusted for the length of the specimen and the other is driven to apply the load to the test specimen. The test process involves by placing the test specimen in the testing machine with a gauge length of $100 \mathrm{~mm}$. Then load is applied gradually and specimen starts bending until the specimen breaks. During the application of loading, the elongation of the specimen is recorded against the applied load.

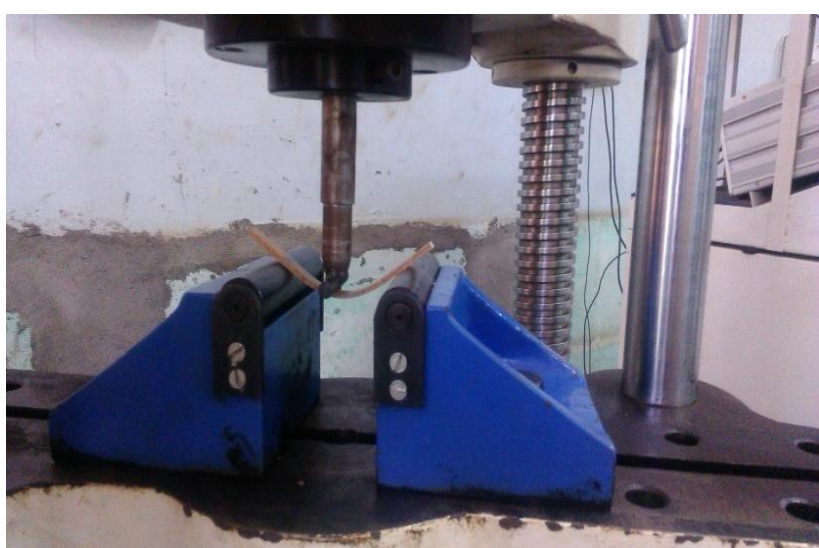

Figure 3: Arrangement of bending test

The above figure 3 shows the experimental set up for the bending test, which consists of three points loading. Three points' arrangements means, one point is at loading and other two points are at fixed.

\subsection{Experimental Result}

By conducting flexural test on universal testing machine we have recorded the following results.

Table 1: Deformation from mechanical tests

\begin{tabular}{|c|c|c|c|}
\hline \multicolumn{2}{|c|}{} & \multicolumn{2}{|c|}{ Flexural test } \\
\hline \multirow{4}{*}{ Specimen } & $\begin{array}{c}\text { Load } \\
(\mathrm{kN})\end{array}$ & $\begin{array}{c}\text { Deformation } \\
(\mathrm{mm})\end{array}$ \\
\hline \multirow{4}{*}{$\mathbf{1 \%} \%$} & MEAN & 0.12 & 6.06 \\
\cline { 2 - 4 } & $\mathbf{A}$ & 0.12 & 6.52 \\
\cline { 2 - 4 } & $\mathbf{B}$ & 0.10 & 6.60 \\
\cline { 2 - 4 } & $\mathbf{C}$ & 0.14 & 6.62 \\
\cline { 2 - 4 } & MEAN & $\mathbf{0 . 1 2}$ & $\mathbf{6 . 5 8}$ \\
\hline \multirow{4}{*}{$2 \%$} & $\mathbf{A}$ & 0.10 & 6.40 \\
\cline { 2 - 4 } & $\mathbf{B}$ & 0.12 & 6.70 \\
\cline { 2 - 4 } & $\mathbf{C}$ & 0.18 & 6.86 \\
\cline { 2 - 4 } & MEAN & $\mathbf{0 . 1 3 3}$ & $\mathbf{6 . 6 5}$ \\
\hline
\end{tabular}

From the above table 1 it is clearly observed that with increase in the glass fiber percentages, the deformation goes on increases with increasing in the load.

The following figure 4 clearly shows that with increase in the load, the deformation also goes on increases.

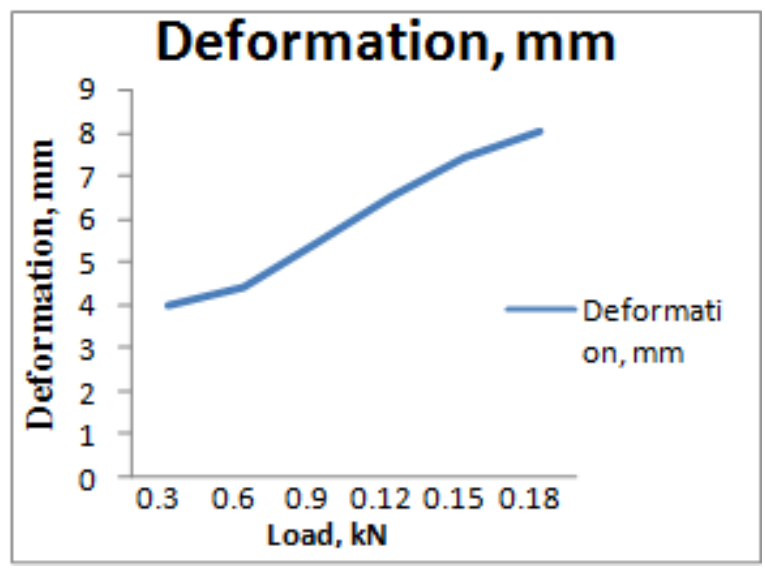

Figure 4 Bending test deformation for $1 \%$

\section{Volume 4 Issue 12, December 2015}




\section{International Journal of Science and Research (IJSR) \\ ISSN (Online): 2319-7064}

Index Copernicus Value (2013): 6.14 | Impact Factor (2014): 5.611

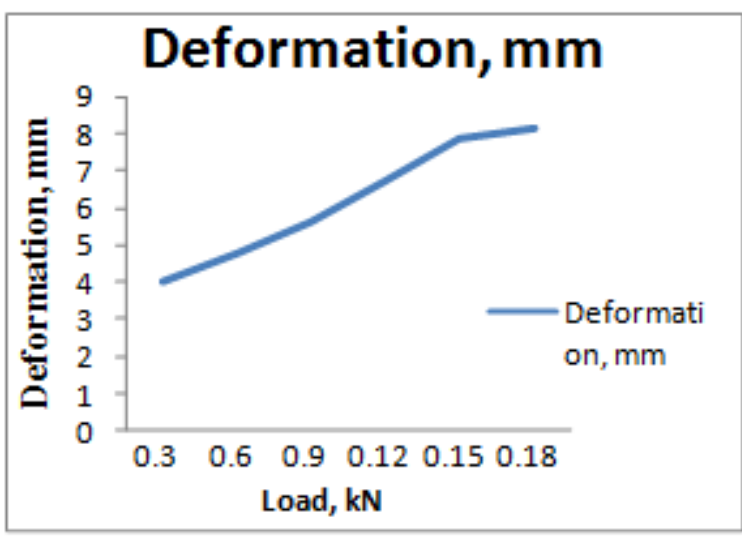

Figure 5: Bending test deformation for 2\%

Figure 5 clearly shows that with increase in the load, the deformation also goes on increases.

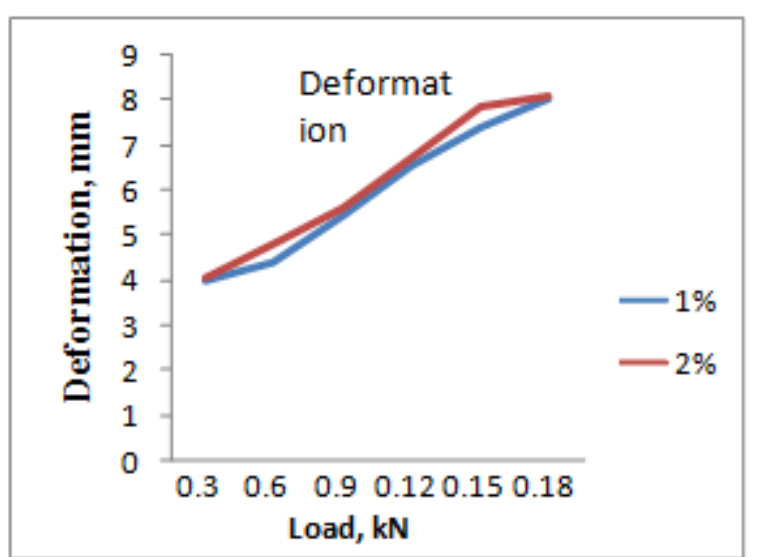

Figure 6: Mean deformations for bending test for $1 \%$ \& $2 \%$

Figure 6 clearly shows that with increasing the percentage of glass fiber content, the deformation also goes on increasing. Figure 4 and figure 5 shows that the deformations for different percentage variations of glass fiber contents. Fig 6 shows that mean deformation in different percentage variations of glass fiber contents; it has observed that the maximum deformation occurs at $2 \%$ of glass fiber contents which increases the load bearing capacity.

\section{Strength and Modulus}

From the experimental values we calculated the bending strengths of the pure epoxy and various percentages $1 \%$ and $2 \%$ of the composite materials and also the modulus of the composite materials as shown in the above table. From using these values we plotted the effect of glass fiber content on tensile strength of various percentages as shown below

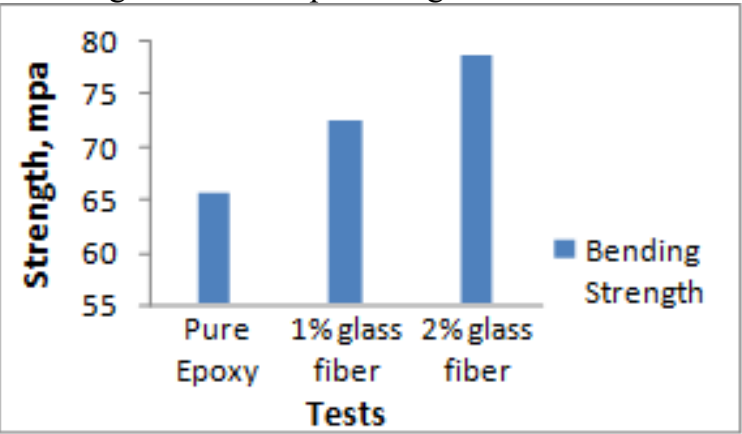

Figure 7: Effect of glass fiber content on bending strength of various percentages
Above fig shows the effect of glass fiber content on bending (flexural) strength of various percentages (pure epoxy, $1 \%$ \& $2 \%$ ) of glass fiber. The bending strength of composite material increases with increasing the percentage of glass fiber content. From the above fig the bending strength for $2 \%$ is more than the epoxy pure and $1 \%$.

\section{Failure Analysis}

The following figure shows the fracture pattern of bending samples tested under the $1 \%$ and $2 \%$ configurations

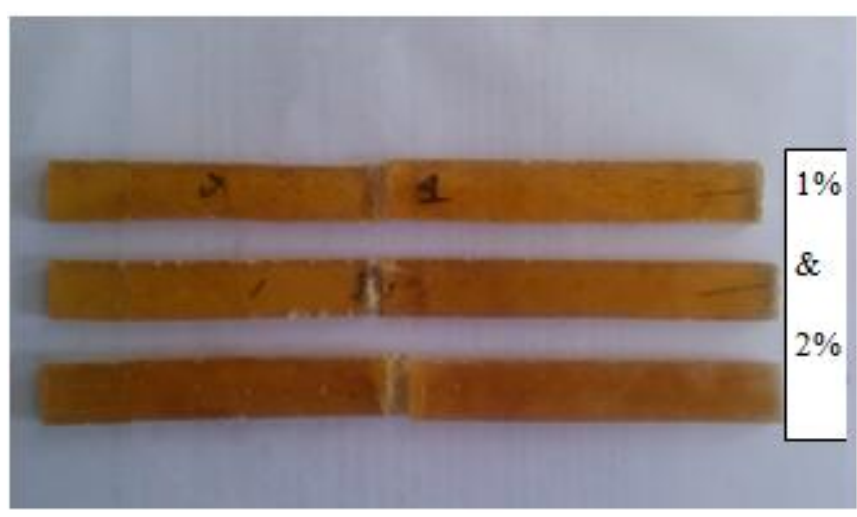

Figure 7: Fractured samples with different configurations.

The fig shows the fracture pattern of bending samples tested under the $1 \%$ and $2 \%$ configurations. In all cases the crack has initiated at the mid - span of the specimen. The failure starts at the tensile side of the specimen, with the central loading and developed towards the compressive side of the specimen. Hence, the deformation and fracture analysis are governed by the tensile properties of these specimens.

\section{Conclusion}

The present work concludes the successful preparation of composite materials by using the $\mathrm{E}$ glass fiber reinforced epoxy composite testing of new class of epoxy composites reinforced with using the glass fiber and the bisphenol $\mathrm{A}$ as a matrix material is done. Proportionately the flexural (bending) strength can be increases with increasing in the percentage $(\%)$ of glass fiber contents. Also the failure starts at the tensile side of the specimen, with the central loading and developed towards the compressive side of the specimen. Hence, the deformation and fracture analysis are governed by the flexural properties of these specimens.

\section{References}

[1] Sudhir S Mathapati, Tushar Hawal, Prashant kakamari: Analysis and characterization of Tensile and Compressive Properties of the Chopped Strand Mat E-Glass Fiber Reinforced Epoxy Composites, volume4, issue3, pages 29-33 2014.

[2] Dr. P. K. Palani, M. N Andakumar: Analysis of Mechanical Properties of Chopped Strand Mat E-Glass Fiber Epoxy Resin Nanoclay Composites, Volume2, Issue 2, Pages 185-189 2013.

[3] Sudhir S Mathapati, Shivukumar S Mathapati: Evaluation of compressive properties of chopped strand mat e-glass

\section{Volume 4 Issue 12, December 2015}


fiber reinforced epoxy composite, volume2, issue3, pages 122015.

[4] Mohd. Zulfli, N. H., Abu Bakar A. and Chow W. S. and thermal behaviors of glass fiber reinforced epoxy hybrid composites containing oregano-montmorillonite, Vol. 7 2012.

[5] X. Huang, X. Yu, C. Wang, G. Li, Y. Song, K. Lu, E. Niu, C. Gung, N. Clayton, and M. Su, Inter laminar Shear Strength Property of the Glass Fiber/Polyimide Reinforced Epoxy Resin for ITER Feeder Mock-ups, vol. 24, no. 3, june 2014.

[6] ASTM D 790-02, Standard test method for Flexural properties of unreinforced and reinforced plastics and electrical insulating materials.

\section{Authors Profile}

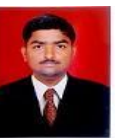

Sudhir Shekhar Mathapati has received the B.E. Degree in Automobile Engineering from B.L.D.E.A's Dr. P.G. Halakatti College of Engineering Bijapur, under VTU, Belagavi, Karnataka in the year 2012 and MTech. Degree in Mechanical Engineering with specialization in Computer Integrated Manufacturing from Gogte Institute of Technology, Belagavi under VTU, Karnataka in the year 2014, respectively. He has published number of international journal papers in field of composite materials and design \& manufacturing field. He is presently working as an Assistant Professor in the Department of Mechanical Engineering, G.H. Raisoni Institute of Engineering \& Technology, Pune.

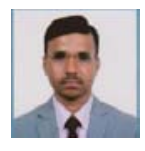

Dr. Suresh B has obtained his B.E. Degree from P.E.S. College of Engineering, Mandya, M.Tech. Degree from P.E.S. College of Engineering, Mandya and Ph.D from Rajiv Gandhi Technological University, Bhopal, Madhya Pradesh. He has more than 19 years of teaching experience. His area of research is hydrodynamic modeling of cyclone separator, mineral processing and composite materials. He has published number of international journal papers in field of mineral processing composite materials. He is presently working as an Associate Professor in the Department of Mechanical Engineering, G.H. Raisoni Institute of Engineering \& Technology, Pune. 